\title{
An audit of violent incidents in a drug treatment centre
}

Sabina Fahy, Roy Brown, Darina Sloan, Shay Keating \& John O'Connor

Ir J Psych Med 17(I): 29-33

\author{
*Sabina Fahy, Senior Registrar in Psychiatry, Department of \\ Psychiatry, University College Hospital, Galway, Ireland. \\ Roy Browne, Senior Registrar in Psychiatry, St Davnet's \\ Hospital, Monaghan, Ireland. \\ Darina Sloan, Consultant Psychiatrist, St Ita's Hospital, \\ Portran:, Co Dublin, Ireland. \\ Shay Keating, Consultant Psychiatrist, John O'Connor, \\ Consultant Psychiatrist, Drug Treatment Centre, Trinity Court, \\ 30/31 Pearse Street, Dublin 2, Ireland.
}

*Correspondence

SUBMITTED: JULY 10, 1999. ACCEPTED: FEBRUARY 11, 2000.

\begin{abstract}
Objectives. The aim of this study was to examine the prevalence of, and factors associated with violence in a drug treatment centre.

Method: This study is a retrospective audit of all incident forms completed at an urban drug treatment centre between December 1991 and July 1996 with reference to case notes for additional clinical information on individuals involved in violent incidents.

Participants included all patients attending the centre in the aforementioned time period who were involved in violent incidents. Information was obtained about the prevalence and severity of violent incidents and patient details including main drug of abuse, route of use, reason for attendance, comorbid axis 1 diagnosis, history of previous incidents and HIV status at the time of the incident.
\end{abstract}

Results: One per cent of all patients were involved in violent incidents. Less than one quarter of incidents involved serious injury or assault. Most perpetrators were male intravenous heroin users on a methadone maintenance programme. Nurses and doctors were most frequently the victims of incidents. Ten per cent of patients had a history of previous incidents and almost half the perpetrators were HIV positive. A comorbid axis 1 diagnosis was found in $9 \%$ of perpetrators $(n=6)$, mainly alcohol dependence syndrome. 
Conclusions: Those on methadone maintenance programmes were most likely to be violent. Almost half the perpetrators involved in violent incidents were HIV positive. Acute psychiatric problems did not account for violence in this setting. The presence of on site security staff probably accounted for the low levels of violence when compared to general psychiatric settings.

\section{Introduction}

There is no standardised definition of violence. Fottrell ${ }^{1}$ described it as, "a generic word bedevilled by the lack of a universally accepted definition". It can include verbal abuse, property damage, assault or even life threatening injury.

Whatever the definition used violence is now a recognised problem in Accident and Emergency Departments ${ }^{2} 3$, psychiatric hospitals and units ${ }^{46}$ among psychiatric patients in the community, ${ }^{7}$ and special hospitals.

There is a public perception that drug users are violent which is supported in the literature. ${ }^{11-13}$ Previous drug use and criminal record have been implicated as an associated factor for violence in a general psychiatric setting. ${ }^{5,14-16}$ The aim of this study was to examine all recorded violent incidents and assess prevalence rates and identify factors associated with violence in this setting.

\section{Background}

The Drug Treatment Centre is an urban based outpatient facility in Dublin (Ireland) for the specialised assessment and treatment of persons with substance abuse. It has an average annual attendance of 47,160 (an attendance is defined as each visit by a patient). This constitutes an average of 1,500 patients per year. Seventy-six per cent of those attending are male while $24 \%$ are female. The centre has a staff complement of one consultant psychiatrist and five junior doctors. Also there is a nursing team (a nursing officer and two staff nurses), four social workers and three general assistants. There are two secretarial staff to whom all patients report on their arrival.

After a full assessment a suitable programme is offered ranging from supportive counselling, detoxification, maintenance, or harm reduction. The harm reduction programme consists of patients attending three nights per week between 6.00pm9.00pm. It aims to encourage attendance at the centre with standard low dose methadone without strict urine supervision. This allows access to medical care, needle exchange and advice on contraception for those whom it is felt would be 
unable to comply with a more strict regime. All other patients attend the clinic daily and give twice weekly supervised urine samples with additional random testing.

At any given time the proportion of people attending each programme is as follows:

- maintenance (substitution) programme 70\%

- detoxification programme $15 \%$

- harm-reduction (night) programme 15\%

These proportions may vary from time to time depending on clinical needs at the center. All patients must check in at the secretary's desk so that their chart can be obtained. Patients wait in a common waiting area which is supervised by security personnel. In general, patients are seen in individual offices unless it is felt that there is a potential for confrontation or violence in which case the interview takes place in the corridor adjacent to the waiting area out of earshot of other patients but within sight of the security personnel.

Patients are seen by the doctor at initial assessment and are subsequently seen for review regarding clinical status which may entail alerting the patient to a urine sample found positive for various drug groups.

This often results in a reduction or change of medication. In the event of continued positive urines (despite warnings) and a decision from the daily team meeting, it is the doctor's duty to inform the patient of a discontinuation of their programme. In this event they must wait for a further three months before again applying for a place on the programme.

The patients have daily contact with nursing staff who dispense medications. In addition the nursing staff may decide that a particular individual needs to be reviewed by the doctor depending on their clinical presentation or urine status.

Patients are assessed by social workers for social welfare benefits and other entitlements and would sometimes represent the patient as advocates in the setting of a team meeting. They also involve patients in family therapy and sometimes assist in protection of children where appropriate. The amount of time that a social worker spends with each patient varies greatly depending on individual needs.

All incidents of violence at the Drug Treatment Centre have been recorded from December 1991. The incident forms record demographic information and details of the incident and aggressor. All violent incidents are discussed at the daily team meeting. Depending on the severity of the current incident and evidence of previous 
incidents this results in some patients being placed on a behavioural review list. This entails being barred from the clinic, which is under monthly review, by the team. Since 1992 on site security has been provided by a professional security firm.

\section{Method}

Incident forms were examined retrospectively from December 1991 to July 1996. Data was collected about individual incidents regarding time and location of incident, demographics of perpetrator and person towards whom violence was directed. Details of the main drug of abuse, route of use, other prescribed medication, reason for attendance, comorbid axis I psychiatric diagnosis, history of previous incidents and HIV status at the time of the incident were obtained from their medical notes. Violence was graded depending on severity. Grade 1 was defined as verbal abuse or antisocial behaviour, Grade 2 as property damage and Grade 3 as assault/injury. Data was then coded, computerised and analysed using SPSS

\section{Results}

The perpetrators comprised 46 men and 19 female (the gender of two patients was not identified). This group had a mean age of 28.4 years (range 19-42 years). There were 75 incidents committed by 67 patients. Seven had one previous incident and three had two previous incidents.

Most incidents occurred during weekdays, between 9.00am and 5.00pm (89.3\%, n $=72)$ and in the waiting area $(29 \%, n=22)$ or nurses station $(28 \%, n=21)$. Most incidents occurred in 1992 with a decline following the introduction of on-site security (Fig 1).

At the time of the incident, $97 \%$ of perpetrators $(n=73)$ were using intravenous heroin. Forty-seven per cent $(n=35)$ were on a substitution programme, $24 \%(n=$ 18) were on a detoxification programme, $17 \%(n=13)$ were on a harm reduction program, and $11 \%(n=8)$ had an 'other' reason for attendance. 


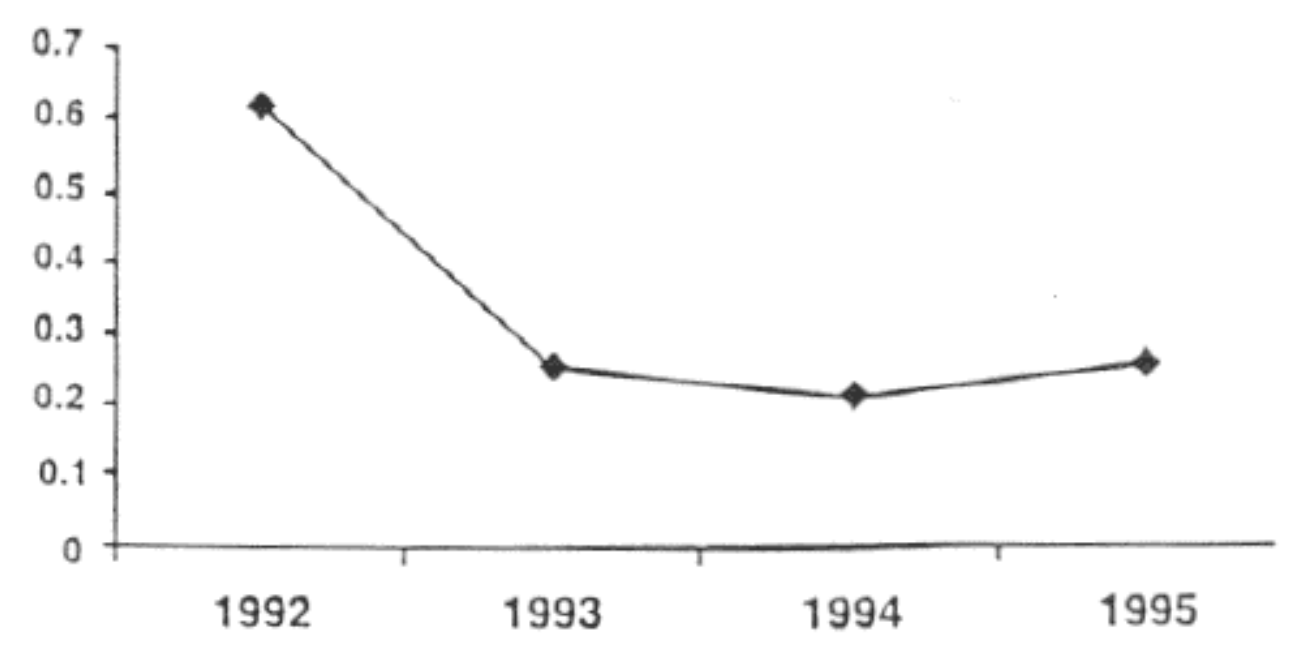

$\begin{array}{lccr}\text { Year } & \text { Incidents } & \text { Attendances } & \begin{array}{r}\text { Incidents } \\ 1,000 \text { attend }\end{array} \\ 1992 & 28 & 44,949 & 0.62 \\ 1993 & 10 & 39,736 & 0.25 \\ 1994 & 11 & 50,431 & 0.22 \\ 1995 & 15 & 56,753 & \mathbf{0 . 2 6}\end{array}$

Nurses, doctors and other patients were significantly more involved in incidents, $\left(X^{2}\right.$ $=13.6, \mathrm{df}=6, \mathrm{p}=0.03$ ) (Fig 2). Six perpetrators had a comorbid axis 1 psychiatric diagnosis, five of alcohol dependence syndrome and one of schizophrenia. Eight perpetrators $(11 \%)$ were on other prescribed medication at the time of the incident. These included inhalers, antipsychotics and antiepileptic medication.

The HIV status of 17 perpetrators (23\%) was not known at the time of the incident. Thirty-seven perpetrators (49\%) were HIV positive (whilst the HIV positive rate for the total clinic population was $2 \%$ ) and 17 were HIV negative (28\%). Significantly more males were HIV positive 30:7 $\left(X^{2}=5.3, d f=1, p=0.02\right)$.

Fifty-seven percent $(n=43)$ of incidents were of type I severity, 20\% $(n=15)$ were type 2 severity and $23 \%(n=17)$ were type 3 , which constituted either an assault or injury. The maintenance group had more Type 3 incidents $\left(X^{2}=7.2, d f=1, p=\right.$ 0.007).

In $51 \%(n=38)$ incidents perpetrators were placed on a behavioural review list. In 
$43 \%(n=32)$ incidents a warning was given and the outcome was unknown in $5 \%(n$ $=5)$ cases.

\section{Discussion}

The overall rate of violence was $0.03 \%$ of all attendances which constitutes $1 \%$ of patients who attended the clinic annually. This rate was much lower than rates reported in general psychiatric settings as was our rate of recidivism at $10 \% .^{5.10 .17}$ In addition less than a quarter of all incidents resulted in serious injury or assault. These findings may be attributable to: a) the introduction of security staff in 1992 acting as a possible deterrent (Fig 1), b) behaviour modification programmes in existence at the centre resulting in sanctions depending on behaviour, c) underreporting of incidents due to the retrospective nature of the study. ${ }^{18}$ The study demonstrated increased prevalence of male perpetrators which reflects the male/female distribution that exists at the clinic generally. D'Orban ${ }^{19}$ cites a male: female ratio of 9:1 for violence against the person in the UK. A study by Larkin ${ }^{10}$ referring to a special hospital found an increased rate of violence in women patients.

The decrease in incidents at weekends concurs with previous studies and probably reflects fewer changes in clinical management or medication. ${ }^{5}$

Doctors were involved in almost as many incidents as nurses (Fig 2). However, there are twice as many medical staff at the centre than nursing staff so the comparative risk to nurses is greater. Other studies of violence also show nurses in the majority. ${ }^{5.6 .}$ The increased risk of violence towards nurses and doctors probably reflects the type of interaction they have with the drug abuser. As expected, nurses were involved in almost a quarter of all incidents, indicative of the amount of total contact with the patient in initial contact and dispensing of medications.

The doctors' role involves informing the patient of discontinuation of their programme and warnings regarding positive urines which can be potentially confrontational particularly in an intoxicated individual. Interestingly social workers were involved in very few incidents despite regular and frequent contact with some individuals. Social workers were probably perceived by the drug abuser in a more supportive and less potentially confrontational role than either nurses or doctors.

Intravenous heroin was the most common primary drug of misuse reflecting the drug using patterns of the general population at that time (Drug Treatment Centre 
Board Statistics for 1992-1995). The majority of perpetrators (48\%) were on a methadone maintenance programme reflecting the overall proportions attending the clinic (ie.70\% of all clinic patients are on a substitution programme). interestingly, a higher proportion of detoxification patients (24\%) were involved in incidents (as opposed to $15 \%$ of the general clinic population). This may be related to their difficulty in coping with opiate detoxification.

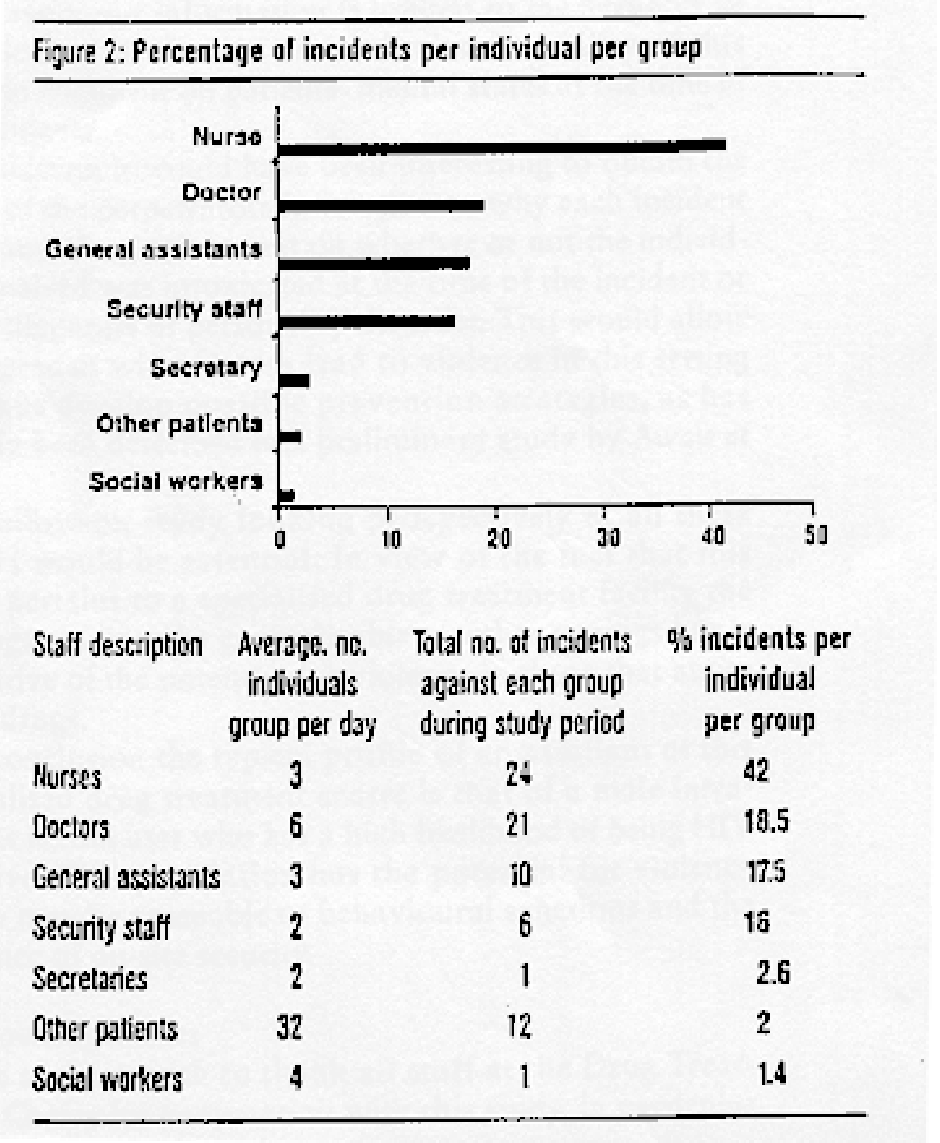

Almost half the perpetrators were HIV positive which is much higher than the rate of $2 \%$ for the overall clinic population. This finding may indicate antisocial personality traits or chronicity of drug use among the violent group. A diagnosis of antisocial personality disorder has previously been found to increase the risk of sharing injection equipment with increased rates of HIV. ${ }^{20 .}$ Organic factors might also be contributory. In addition these HIV positive patients may reflect a sub-group who have a higher risk taking potential in general and thus perceive that they have little to lose by being confrontational. Further prospective study of these hypotheses may 
elucidate possible cause and effect factors as to the high proportion of HIV positive perpetrators of violence.

Only $9 \%$ of patients were found to have a comorbid axis I psychiatric diagnosis and all but one of these patients suffered from alcohol dependence syndrome. This suggests that acute psychiatric symptoms did not account for the violence seen in this setting of a specialised drug treatment centre but the co-abuse of alcohol does contribute to the potential for violence in this population.

As a result of these findings a contract has recently been introduced. This lists behaviours that are deemed to be unacceptable and outlines the consequences of same. Each client is required to sign the contract before the initiation of their treatment programme and this is kept in their chart for reference in the event of any changes in their management.

Some limitations of this study include the fact that it is retrospective and as such our information obtained from the incident forms and chart reviews may be incomplete. By necessity out information is limited to the accuracy of historical clinical notes which limits the ability of this study to comment on patients' mental states at the time of the incidents.

In addition it would have been interesting to obtain the views of the perpetrators in relation to why each incident arose and also to comment on whether or not the individual involved was intoxicated at the time of the incident or had a diagnosis of personality disorder. This would allow us to predict what factors lead to violence in this setting and thus develop possible prevention strategies, as has already been described in a preliminary study by AwaIt et al. 21.

A follow-on study looking prospectively at all these factors would be essential. In view of the fact that this study pertains to a specialised drug treatment facility the findings may not be generalisable to other settings but is indicative of the potential for violence in those that abuse illicit drugs.

In conclusion the typical profile of an assailant at this specialised drug treatment centre is that of a male intravenous heroin user who has a high likelihood of being HIV positive. This population has the potential for violence which may be amenable to behavioural sanctions and the presence of on-site security.

\section{Acknowledgements}

The authors wish to thank all staff at the Drug Treatment Centre for co-operation with this study, in particular the secretarial and nursing staff. 


\section{References}

1. Fottrell E. A study of violent behaviour among patients in psychiatric hospitals. BL Psych 1980: 136:216-21

2. Wyatt JP, Watt M. Violence towards junior doctors in accident and emergency departments, J Acc Emerg Med 1995: 12: 40-2

3. Cembrowicz SP, Shepard JP. Violence in the accident and emergency department. Med Sci Law 1992: 32(2): 118-22

4. Schwartz TL, Park TL. Assaults be patients on psychiatric residents: a survey and training recommendations. Psychiatr Serv 1999: 50(3): 381-3

5. Walker Z, Seifert R. Violent incidents in a psychiatric intensive care unit. B J Psych 1994: 164: 826-8

6. Aquilina C. Violence by psychiatric in patients. Med Sci Law 1991:31(4):306-12

7. Streadman HJ. Mulvey EP. Monahan J et al. Violence by people discharged from acute psychiatric inpatient facilities and by others in the same neighbourhoods. Arch Gen Psychiatry 1998: 55: 393-401

8. Scott H. Johnson S. Menezes $P$ et al. substance misuse and the risk of aggression and offending among the severely mentally ill. B J Psychiatry 1998: 172: 345-50

9. Swanson J. Borum R. Swarrz M Hiday V. Violent behaviour preceding hospitalisation among persons with severe mental illness. Law Hum Behav 1999; 23(2): 185-204.

10. Larkin E. Murtagh S, Jones S. A preliminary study of violent incidents in a special hospital (Rampton). B J Psych 1988; 153:226-31.

11. Ball JC. Rosen L. Flueck JA. \& Nurco DN. Lifetime criminality of heroin addicts in the United States. J Drug Issues, 1982: 12:225-9. 
12. Kouri EM. Pope HG. Powell KF. Oliva PS. Campbell C. Drug use history and criminal behaviour among 133 incarcerated men. Am J Drug Alcohol Abuse 1997:23(3): 413-9.

13 Hanlon TE, Nuren DN, Kinlock TM, Duszynski KR, Trends in criminal activity and drug use over an addiction career. Am J Drug alcohol Abuse 1990:16: 223-38

14. Tardiff K, Marzuk PM, Leon AC, Portera L, Weiner C. Violence by patients admitted to a private psychiatric hospital. Am J Psychiatry 1997:154(1):88-93

15. Cuffel BJ, shunway M, chouljian $T L$, MacDonald $T$. A longitudinal study of substance use and community violence in schizophrenia. J Nerv Ment Dis 1994:182:704-8

16. Swartz MS, Swanson JW, Hiday VA, Borum R, Wagner HR, Burns BJ. Violence and severe mental illness: the effects of substance abuse and nonadherence to medication. Am J psych 1998: 155(2): 226-31

17. James DV, Fineberg NA, Shah AK, Priest RG. An increase of violence on an acute psychiatric ward: a study of associated factors. B J Psych 1990: 156:846-52

18. Haller RM, Deluty RH. assaults on staff by psychiatric in-patients - a critical review. B J Psych 1988:152:174-9

19 D'Orban P. Female Offenders. In: Gunn J, Taylor P (eds). Forensic Psychiatry Clinical. Legal and Ethical Issues. Butterworth Heinemann 1993:600.

20. Brooner RK, Bigelow GE, Strain E, Schmidr CW. Intravenous drug abusers with anti-social personality disorder: increased HIV risk behavior. Drug AlcoholDepend 1990:26(1): 39-44

21. Awalt RM, Reilly PM, Shopshire MS. The angry patient: an intervention fro managing anger in substance abuse treatment. J Psychoactive Drugs 1997: 29(4): 353-8 


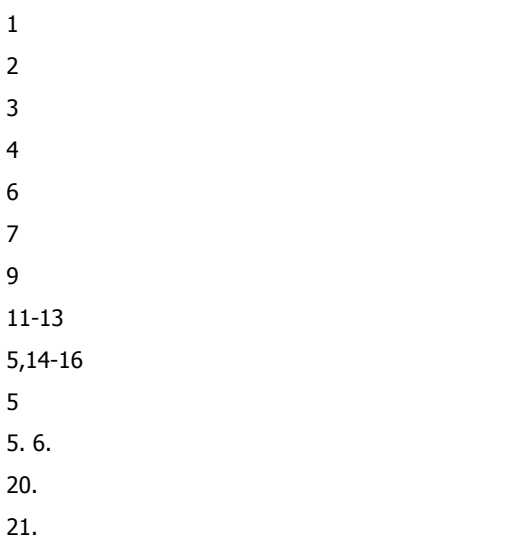

This article is a reproduction of that published in: Irish Journal of Psychological Medicine, 17(1), 2000, pp.29-33. Pagination may not match that of the original. 